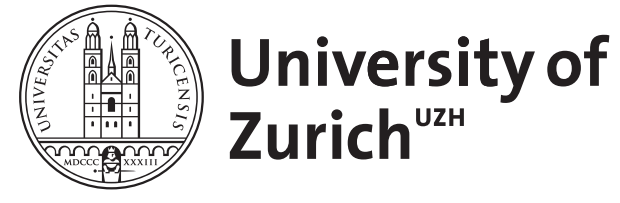

\title{
High Density Lipoprotein - Should we Raise it?
}

\author{
Landmesser, Ulf
}

\begin{abstract}
Low high-density lipoprotein (HDL) cholesterol levels are associated with an increased risk of coronary artery disease and myocardial infarction. Experimental studies have identified several potential anti-atherogenic properties of HDL, including promotion of macrophage cholesterol efflux, endothelial nitric oxide stimulation, anti-inflammatory and anti-thrombotic effects. These observations have lead to the important question of whether raising of HDL can reduce cardiovacular risk. Notably, recent studies have suggested that vascular effects of HDL can be highly heterogenous and are altered in patients with coronary disease or diabetes, that has been referred to as "HDL dysfunction". Moreover, studies using gene-targeted mice have indicated that genetic modifications leading to a similar increase of HDL cholesterol levels can either reduce (i.e. apoA1 transgene overexpression) or accelerate (i.e. SR-B1 deficiency) atherosclerosis, depending on the molecular target. These findings therefore suggest that HDL cholesterol levels alone are likely not sufficient as a readout for the vascular effects of HDL-targeted therapeutic interventions, since both, the vascular effects of on-treatment HDL as well as the underlying molecular mechanism used to elevate HDL cholesterol levels may represent critical determinants of the overall vascular effects of therapeutic interventions raising HDL-cholesterol levels. In summary, low HDL cholesterol plasma levels remain associated with an increased cardiovascular risk. However, the above findings suggest that careful clinical trial programms are needed to determine, which HDL raising therapeutic interventions may indeed exert vasoprotective effects.
\end{abstract}

DOI: https://doi.org/10.2174/157016112803520710

Posted at the Zurich Open Repository and Archive, University of Zurich

ZORA URL: https://doi.org/10.5167/uzh-69557

Journal Article

Originally published at:

Landmesser, Ulf (2012). High Density Lipoprotein - Should we Raise it? Current Vascular Pharmacology, 10(6):718-719.

DOI: https://doi.org/10.2174/157016112803520710 


\title{
High Density Lipoprotein -
}

\section{Should We Raise It ?}

\author{
Ulf Landmesser, MD, FESC
}

Cardiology, Cardiovascular Center, University Hospital Zurich and

Zurich Center for Integrative Human Physiology, University of Zurich,

Zurich, Switzerland

\author{
Address for correspondence: \\ Ulf Landmesser, MD \\ University Hospital Zurich \\ Cardiovascular Center \\ Raemistrassse 100 \\ 8091 Zurich \\ SWITZERLAND \\ Phone: 0041-44-255-9595 \\ Fax: 0041-44-255-4251 \\ Ulf.Landmesser@usz.ch
}

Keywords: High density lipoprotein; Endothelium; Inflammation; Coronary Artery Disease 


\begin{abstract}
Low high-density lipoprotein (HDL) cholesterol levels are associated with an increased risk of coronary artery disease and myocardial infarction. Experimental studies have identified several potential anti-atherogenic properties of HDL, including promotion of macrophage cholesterol efflux, endothelial nitric oxide stimulation, anti-inflammatory and anti-thrombotic effects. These observations have lead to the important question of whether raising of HDL can reduce cardiovacular risk.
\end{abstract}

Notably, recent studies have suggested that vascular effects of HDL can be highly heterogenous and are altered in patients with coronary disease or diabetes, that has been referred to as "HDL dysfunction". Moreover, studies using gene-targeted mice have indicated that genetic modifications leading to a similar increase of HDL cholesterol levels can either reduce (i.e. apoA1 transgene overexpression) or accelerate (i.e. SR-B1 deficiency) atherosclerosis, depending on the molecular target.

These findings therefore suggest that HDL cholesterol levels alone are likely not sufficient as a readout for the vascular effects of HDL-targeted therapeutic interventions, since both, the vascular effects of on-treatment HDL as well as the underlying molecular mechanism used to elevate HDL cholesterol levels may represent critical determinants of the overall vascular effects of therapeutic interventions raising HDL-cholesterol levels.

In summary, low HDL cholesterol plasma levels remain associated with an increased cardiovascular risk. However, the above findings suggest that careful clinical trial programms are needed to determine, which HDL raising therapeutic interventions may indeed exert vasoprotective effects. 
Coronary artery disease remains the leading cause of death in the developed countries. Moreover, the risk of cardiovascular complications, such as myocardial infarction, remains substantial despite current optimal medical therapy in patients after an acute coronary syndrome (1). Therefore, novel approaches to reduce cardiovascular risk are intensely examined, and HDL has received great attention as a potential novel therapeutic target.

Low levels of HDL are associated with an increased cardiovascular risk (2). Moreover, several mechanisms have been identified whereby HDL may exert anti-atherosclerotic effects. Initially, reverse cholesterol transport by HDL has been suggested as a potential antiatherosclerotic mechanism of HDL (3) and the molecular mechanisms whereby HDL promotes macrophage cholesterol efflux have been identified, in particular the ABCA-1 and ABCG-1 transporters (4). Later it was shown that HDL exhibits direct effects on vascular cells, in particular endothelial cells, that could represent anti-atherogenic properties of HDL, such as the capacity of HDL to stimulate endothelial cell nitric oxide (NO) production, to promote endothelial repair and to exert anti-inflammatory and anti-thrombotic effects (5-7).

Importantly, however, more recent evidence has suggested that the effects of HDL on macrophage cholesterol efflux and in particular the endothelial effects of HDL can be highly heterogeneous, and are altered in patients with coronary disease or diabetes, that has also been referred to as "HDL dysfunction". In this respect, Khera et al. have reported that the cholesterol efflux capacity of apoB-depleted serum (as a measure of the capacity of HDL to accept cholesterol from macrophages) was inversely related to carotid intima-media thickness and the likelihood of angiographic coronary artery disease that was independent of the HDL cholesterol levels (8). We have observed that that the capacity of HDL to stimulate endothelial NO production or endothelial repair mechanisms is substantially impaired in patients with coronary disease or diabetes $(7,9)$. HDL isolated from healthy subjects sunstantially stimulated endothelial cell NO production and accelerated endothelial repair in 
vivo, whereas no such effects were observed, when HDL was isolated from patients with coronary disease or diabetes $(7,9)$. The underlying mechanisms need to be further defined, but likely include increased lipid oxidation of HDL due to a reduced HDL-associated paraoxonase-1 activity, an enzyme that protects HDL from lipid oxidation. Moreover, HDL is a highly complex lipoprotein that has likely more than 70 associated proteins, as identified by proteomics analysis (10) and consists likely of more than 1000 different lipid species (Figure). Therefore, the vascular effects of HDL are not necessarily predicted by the HDL cholesterol levels, since cholesterol is only one lipid component of the lipoprotein. These observations also raise the possibility that vascular effects of on-treatment HDL may be an important determinant of the overall vascular effects of an HDL-raising intervention.

Moreover, it has been realized that the HDL metabolism, i.e. HDL synthesis, transfer and uptake mechanisms, are complex, and HDL cholesterol levels can therefore be raised by multiple interventions, either promoting HDL synthesis, preventing transfer of HDL components (such as cholesterol ester transfer protein - CETP - inhibition) or by prevention of uptake of HDL cholesterol (such as SR-BI inhibition). Interestingly, experimental studies in mice have suggested that transgenic overexpression of human apolipoprotein-A-I, the major protein component of HDL, increased HDL cholesterol levels and reduced development of atherosclerosis (11). In contrast, however, raising HDL cholesterol by inhibition of the Scavenger receptor class B type I (SR-BI), that mediates uptake of HDLcholesterol and cholesteryl ester in the liver and steroidogenic tissues, resulted also in increased HDL cholesterol levels, but at the same time was associated with an accelerated atherosclerosis development in mice (12). Notably, the SR-BI receptor is also expressed on endothelial cells, and likely mediates several of the endothelial-protective effects of HDL, such as stimulation of endothelial cell NO production and endothelial repair $(5,13)$. Raising HDL cholesterol by SR-BI inhibition may therefore also inhibit the endothelial-protective 
mechanisms exerted by HDL. These studies in gene-targeted mice suggest that interventions that increase HDL cholesterol levels can either reduce or increase atherosclerosis development, depending on the underlying molecular mechanism that leads to elevation of HDL cholesterol levels.

The above observations suggest that HDL cholesterol levels alone are likely not sufficient as a therapeutic target. Both, the on-treatment vascular effects of HDL as well as the underlying molecular mechanism leading to increased HDL cholesterol levels are likely important determinants of the overall vascular effects of an HDL-choelsterol raising therapeutic intervention. Therefore, careful clinical trials are needed for HDL-raising therapies, to determine the overall cardiovascular effects of such interventions. At present, several clinical trial programms are performed, using different CETP-inhibitors (dalcetrapib, anacetrapib, evacetrapib), nicotinic acid/laropiprant (HPS-3 study) or reconstituted forms of HDL. 


\section{Figure legend}

\section{Figure}

HDL consists of more than seventy proteins and likely more than 1000 lipid species, illustrating the complexity of this lipoprotein, that is greater as has been previously considered. This explains why measurement of HDL cholesterol levels alone are likely not sufficient to predict vascular effects of HDL-raising interventions. 


\section{References}

1. Stone GW, Maehara A, Lansky AJ, de Bruyne B, Cristea E, Mintz GS, Mehran R, McPherson J, Farhat N, Marso SP, Parise H, Templin B, White R, Zhang Z, Serruys PW. A prospective natural-history study of coronary atherosclerosis. $N$ Engl J Med. $2011 ; 364: 226-235$

2. Di Angelantonio E, Sarwar N, Perry P, Kaptoge S, Ray KK, Thompson A, Wood AM, Lewington S, Sattar N, Packard CJ, Collins R, Thompson SG, Danesh J. Major lipids, apolipoproteins, and risk of vascular disease. Jama. 2009;302:1993-2000

3. Badimon JJ, Badimon L, Fuster V. Regression of atherosclerotic lesions by high density lipoprotein plasma fraction in the cholesterol-fed rabbit. J Clin Invest. $1990 ; 85: 1234-1241$

4. Tall AR, Yvan-Charvet L, Terasaka N, Pagler T, Wang N. Hdl, abc transporters, and cholesterol efflux: Implications for the treatment of atherosclerosis. Cell Metab. $2008 ; 7: 365-375$

5. Yuhanna IS, Zhu Y, Cox BE, Hahner LD, Osborne-Lawrence S, Lu P, Marcel YL, Anderson RG, Mendelsohn ME, Hobbs HH, Shaul PW. High-density lipoprotein binding to scavenger receptor-bi activates endothelial nitric oxide synthase. Nat Med. $2001 ; 7: 853-857$

6. Nofer JR, van der Giet M, Tolle M, Wolinska I, von Wnuck Lipinski K, Baba HA, Tietge UJ, Godecke A, Ishii I, Kleuser B, Schafers M, Fobker M, Zidek W, Assmann G, Chun J, Levkau B. Hdl induces no-dependent vasorelaxation via the lysophospholipid receptor s1p3. J Clin Invest. 2004;113:569-581

7. Besler C, Heinrich H, Rohrer L, Doerries C, Riwanto M, Shih DM, Chroni A, Yonekawa K, Stein S, Schaefer N, Mueller M, Akhmedov A, Daniil G, Manes C, Templin C, Wyss C, Maier W, Tanner FC, Matter CM, Corti R, Furlong C, Lusis AJ, 
Eckardstein Av, Fogelman AM, Lüscher TF, Landmesser U. Mechanisms underlying adverse effects of hdl on enos-activating pathways in patients with coronary artery disease. J Clin Invest. 2011;121(7)::2693-2708

8. Khera AV, Cuchel M, de la Llera-Moya M, Rodrigues A, Burke MF, Jafri K, French BC, Phillips JA, Mucksavage ML, Wilensky RL, Mohler ER, Rothblat GH, Rader DJ. Cholesterol efflux capacity, high-density lipoprotein function, and atherosclerosis. $N$ Engl J Med. 2011;364:127-135

9. Sorrentino SA, Besler C, Rohrer L, Meyer M, Heinrich K, Bahlmann F, Müller M, Horvath T, Doerries C, Heinemann M, Flemmer S, Markowski A, Manes C, Bahr MJ, Haller H, Von Eckardstein A, Drexler H, Landmesser U. Endothelial-vasoprotective effects of high-density lipoprotein are impaired in patients with type 2 diabetes mellitus but are improved after extended-release niacin therapy. Circulation. 2010;121:110-122

10. Vaisar T, Pennathur S, Green PS, Gharib SA, Hoofnagle AN, Cheung MC, Byun J, Vuletic S, Kassim S, Singh P, Chea H, Knopp RH, Brunzell J, Geary R, Chait A, Zhao XQ, Elkon K, Marcovina S, Ridker P, Oram JF, Heinecke JW. Shotgun proteomics implicates protease inhibition and complement activation in the antiinflammatory properties of hdl. J Clin Invest. 2007;117:746-756

11. Tangirala RK, Tsukamoto K, Chun SH, Usher D, Pure E, Rader DJ. Regression of atherosclerosis induced by liver-directed gene transfer of apolipoprotein a-i in mice. Circulation. 1999;100:1816-1822

12. Huby T, Doucet C, Dachet C, Ouzilleau B, Ueda Y, Afzal V, Rubin E, Chapman MJ, Lesnik P. Knockdown expression and hepatic deficiency reveal an atheroprotective role for sr-bi in liver and peripheral tissues. J Clin Invest. 2006;116:2767-2776 
13. Seetharam D, Mineo C, Gormley AK, Gibson LL, Vongpatanasin W, Chambliss KL, Hahner LD, Cummings ML, Kitchens RL, Marcel YL, Rader DJ, Shaul PW. Highdensity lipoprotein promotes endothelial cell migration and reendothelialization via scavenger receptor-b type i. Circ Res. 2006;98:63-72 